\title{
Competency-based education: Learner's new process for success
}

Cuyacot, Eljim P.

New York City Department of Education, USA (ecuyacot@gmail.com)

Cuyacot, Marilo T.

New York City Department of Education, USA (mcuyacot@bronxinternationalhs.com)

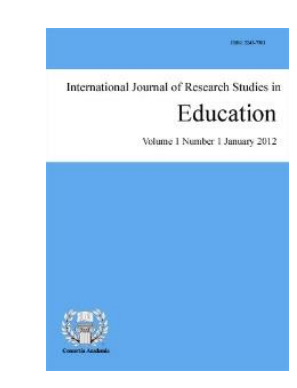

ISSN: $2243-7703$ Online ISSN: 2243-7711

\section{Abstract}

The movement from a "sage-on-the-stage" to a "guide-on-the-side" approach to education doesn't have a single description, but there's one thing for sure: CBE emphasizes outcomes. There have been numerous attempts recently to cultivate a culture of equity and inclusion, as well as to prepare students to live beyond the school walls. However, the question remains, are all schools or even college institutions ready for competency-based curriculum? This will be a challenge for school leaders, but the end result will be better citizens who are more contributing to the community. This will enable all stakeholders to deliver personalized learning that prepares students for the next phase of their lives, whether it is college or the workplace. It could uphold the school's culture, the teachers' pedagogy, the community's involvement, and the success of critical students in transforming their lives. Ultimately, they must be competent global citizens who own their own learning and are willing to share their experiences to influence better decisions.

Keywords: competency-based education, culture of equity, inclusion, personalized, outcomes, challenge, global citizens, stakeholders 


\section{Competency-based education: Learner's new process for success}

\section{Introduction}

In the past few decades, colleges have wondered why most of their incoming students aren't prepared for rigorous academic endeavors. During their time in the schools, few students seem to be able to cope with high stakes activities. As a result, competency-based education is being integrated into more and more schools every year. School culture, structures, and pedagogy will change fundamentally as a result of this change to ensure all students can succeed, regardless of whether they decide to attend college or pursue a career (skilled) pathway. The focus should be on proficiency-based practices, such as putting a high priority on knowledge and skills, providing quality learning experiences aligned to clear outcomes, and guaranteeing that all students have access to support to reach the proficiency standards. For schools to see real benefits for students, families, and teachers alike, they must be better equipped, learn, and identify quality design principles.

It has since become increasingly popular to move away from seat-time and to implement a flexible structure which enables students to progress in their learning once they have demonstrated mastery of the material. Several organizations, districts, and schools have already begun implementing CBE within their respective contexts. As such, understanding the salient traits of competency-based education is paramount to prepare learners, teachers, parents, stakeholders, and even the learning environment before a full implementation occurs.

\section{The New Definition of Competency Based Education}

Although education stakeholders call competency-based systems by many names, including proficiency-based, competency-based, customized, mastery-based and performance-based, these systems are still grading, assessment and academic reporting models that are based on students' mastery of concepts and outcomes. Based on this, learning policies can be designed and implemented, and the goal of the model is to share a common vision of improving students' learning. Instead of learning what students are supposed to do, this system is all about what students are supposed to accomplish. Essentially, this model is about empowering students as advocates for their own learning. Ultimately, student-centered learning matters. As stated in the article titled "Why and How StudentCentered Learning Is Important?" students' increasing ability to decide what material they learn and how they learn signifies the beginning of a new system of teaching and learning. Even so, most student-centered programs adhere to some of the same principles as competency-based education. As a key aspect, both emphasize the importance of using rigorous assessments to gauge a student's performance and making the educational process more meaningful to all students by including teachers, students and the community. Thus, competency-based education focuses more on how competent each student is in a subject than on grades and yearly curriculums. As a result, students can only advance to the next level if they can demonstrate mastery.

\subsection{CBE's Set of Essential Beliefs \& Practices}

It is therefore essential to achieve equitable outcomes and demonstrate mastery of the subject/course by adopting beliefs and practices that identify and describe core activities to foster proficiency, but without these foundational beliefs, these practices will not necessarily create and mold globally competitive and transformative learners. The following beliefs are guides to improving the learning environment, outcomes, feedback (assessment), and pathways to learning.

In general, students benefit from meaningful experiences when they feel included, respected, and valued by their learning community. It is essential for the learning environment to foster relationships between students and adults. The school also recognizes and honors the interests and identities of students, in addition to its curriculum and teaching methods. In this manner, implementing systems and structures that engage and involve all students,

90 Consortia Academia Publishing (A partner of Network of Professional Researchers and Educators) 
families, as well as members of the broader community will uncover and eliminate inequities based on demographics and identity. Taking the example of Bronx International High School, the school celebrates its students' cultures with a day of cultural activities where students demonstrate dances, bring foods, and tell others about their cultures for a whole day. While some students may not feel comfortable sharing their ideas with a structure like this at school, nevertheless there is a positive impact for the majority of the population.

Moreover, it is important to challenge, believe in, and support students in order to achieve high standards. All students have clear, consistent, and long-term learning outcomes, including long-term goals (graduation competencies and performance indicators), short-term goals (learning targets), and habitual behaviors. To achieve competency-based learning, it is necessary to be able to engage in complex thinking and to apply skills and knowledge across content areas. Typically, most of our students at BxIHS will produce at least four projects as part of PBAT that will challenge them to go beyond classroom expectations. In some cases, activities will be done via expository learning, such as going to our partners' workplaces and deciding for themselves how to complete the assignments based on the rubric. When students are not yet proficient, the school should offer interventions, extensions of learning, and opportunities for revision and relearn to help them achieve their goals.

Likewise, learning is facilitated by clear cycles of practice, feedback, assessment, and reflection. A common set of competencies is used to align all forms of assessment. Academic knowledge and skills are assessed separately from habits of work. In addition to promoting practice, self-assessment, and feedback, formative assessment is used to continuously provide students with feedback. Student achievement levels on competencies and performance indicators are determined through summative assessments, which are evaluated following a common scoring framework. It is important to use all forms of feedback (including grades) to adjust learning and teaching, to inform academic interventions, as well as to identify further learning opportunities. Reflecting regularly on learning progress and evaluating oneself is an important part of the learning process. Students are taught to use feedback for improving their learning. Furthermore, students have the choice of engaging in learning experiences that meet their interests. There is a shared set of competencies for all courses, internships, and extended learning opportunities. To meet common goals, we expect and plan for learning in a variety of ways and at a variety of paces in all groups and settings, requiring differentiation and student choice. During the course of a student's learning experiences, they have to make important decisions about how they will demonstrate their skills \& knowledge.

\subsection{Seven Important Elements of $C B E$}

Competency-based education, as explained by Sturgis and Pittenger (2011), includes beliefs that most learners should possess. They group these beliefs into five elements. These are levels of advancement, transparency of learning, assessments, differentiated support and enhance 21 st century skills.

Students will, therefore, be able to devote more time to the subjects they find more difficult as they progress towards mastery. It is possible for them to advance beyond grade level in some domains, while taking longer to master more challenging ones. In addition to maximizing student achievement, mastery also enables the teacher to pinpoint areas where students need extra help and ensure they learn what is needed to advance. Students gain empowerment through measurable, explicit, and transferable learning objectives. As learners gain a greater understanding of learning objectives, they are more likely to own their education and have more choices in what they learn and how they demonstrate it. By doing so, teachers also collaborate more with students since they are more intentional about what they want students to learn. Consequently, assessment is a meaningful and positive learning experience for students. This helps teachers to identify student misconceptions and provide students with the feedback they need to improve. There is flexible time during the day in order to ensure misconceptions are addressed promptly and to provide additional instruction. In such a case, students focus on developing the specific skills they need rather than retaking the entire course. Students, however, are able to develop and apply a wide array of skills and dispositions when they are aware of what they're doing and learning. They can actively acquire critical-thinking and problem-solving skills as well as communication, collaboration, and cultural sensitivity to 
help them work in a constantly changing, diverse workplace. Therefore, 21 st century skills could be put to use in any task they want.

Because of the increasing knowledge and beneficial impacts of CBE, CompetencyWorks (iNACOL) conducted a multi-stage, participatory process from 2017 to 2019, updating the 2011 working definition and adding two more, making it into seven elements today. The National Association for Colleges of Liberal Arts (iNACOL, 2019) says that students can learn actively with different pathways and varied pacing, and that their progress can be based on evidence of mastery, rather than the amount of time they spend sitting. In other words, learning can occur anywhere and at any time. Since COVID is still prevalent nowadays, most schools if not all engage in asynchronous learning. They can engage in them anywhere and at any time because they are available online for students to answer without the teacher's involvement. In New York City, we also have one of the schools which embodies this definition, the Vanguard School in Manhattan, where students can move up to the next grade level when they demonstrate mastery of the previous one. Taking after Vanguard, students will be able to express themselves in a supportive environment, connect with diverse peers, and become confident enough to express themselves. It emphasizes shared accountability, has high expectations for students, uses performance-based assessment to measure their learning, and allows students to complete most activities at their own pace in and out of school.

\subsection{Understanding the Difference between Traditional Education \& $C B E$}

The new architecture of K-12 education is described in this model. In the United States, CBE is becoming increasingly popular in schools. Compared to traditional education, competency-based education is crucial to a student's holistic development for many reasons. Here are a few of those differences.

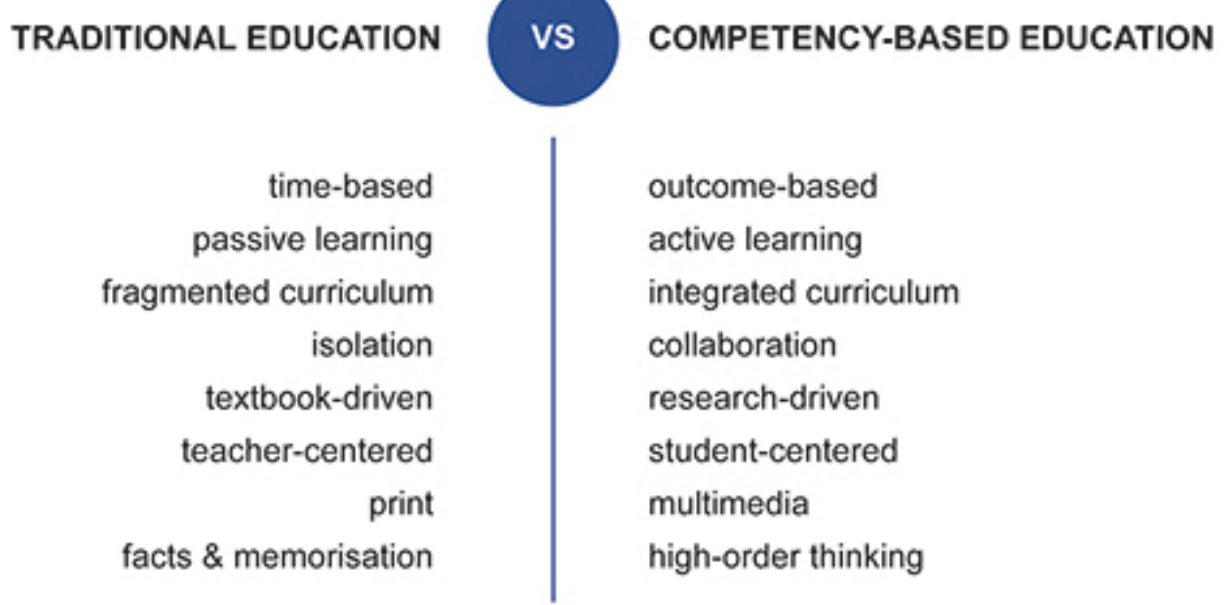

Figure 1: Traditional versus Competency-Based Education. [Source: (Motivis Learning, 2017)]

Tradition would dictate that a learner would use a text book to learn while competency-based education emphasizes active investigation as a means of learning. Contrary to traditional education, where time is fixed and mastery is variable, $\mathrm{CBE}$ is characterized by mastery and time variability. Further, traditional education allows students to learn together regardless of their ability, using the same materials, at the same pace, and should be completed within a school year, regardless of their ability. All students are required to move forward at the end of each unit, regardless of their grasp of the material or their mastery of the necessary skills. Traditionally, learning outcomes have been largely based on memorization and comprehension to pass tests. Since it is a teacher-led type of education, learning is limited. Compared with competency-based learning, it encourages the students to voice their opinions and choices about any lessons or activities they feel most comfortable doing. In this way, CBE is flexible towards its students and can provide them with support to develop their skills, master the subject and move forward. Not only are there paper-pencil tests, but also projects, panel discussions, oral presentations, debates,

92 Consortia Academia Publishing (A partner of Network of Professional Researchers and Educators) 
internships, project outputs, and defense of the project, among other ways to demonstrate mastery. The emphasis is on creating a deeper understanding of concepts and applying them, as well as teaching adult learners the skills necessary to become better learners. It is an exploratory process in which teachers facilitate the learning process and students are continuously challenged at appropriate levels or even above what they are capable of.

\subsection{The Quality Design Principles in Implementing CBE}

The motives behind competency-based education vary among districts and schools: to provide globally competitive graduates, to design schools that promote student learning, to achieve greater equity, to foster continuous improvement in learning, and to foster deeper understanding. If competency-based structures are based on the same beliefs and assumptions as traditional structures, they will fail. In addition, students will not benefit from effective instruction and assessment unless they are firmly grounded in learning science. A school's design is affected by each of the design principles, and other principles are also influenced by each principle. It is crucial that educators are acting as learners (i.e., from professional learning) in order to positively impact teaching and learning, as well as transparency. Consequently, most schools implementing CBE follow three principles in common.

\subsection{Purpose \& Culture, Teaching \& Learning and Structure}

In terms of culture, pedagogy and structures, the school is designed to empower students, build academic knowledge, and engage them in learning that is grounded in real-world situations. A large part of student success outcomes centers on preparing students for college, careers, and lifelong learning. It is essential that students become adept at solving problems on their own and need to use academic skills and knowledge in new contexts.

Districts and schools that are implementing competency-based education have so far aligned themselves around academic content, transferable skills, and the ability of students to become lifelong learners based on these principles. For example, schools employ grading procedures that conceal and obscure students' true learning levels, depriving them of the guidance they need to improve and burdening them with learning gaps that expand and accumulate over time. As an alternative, competency-based districts and schools actively challenge these practices while implementing alternative systems and structures that promote success for all. To ensure that students continue to progress toward success, they become flexible when it comes to using time, resources, and student supports.

Creating inclusive cultures of learning and personalization rather than widening the gap in order to achieve mastery. In order to create high-performing schools, school culture is crucial. Traditionally, school culture focuses heavily on order, safety, and academic excellence. Despite the fact that high achievement is a value shared by competency-based and traditional systems, the way achievement is interpreted varies. Creating an environment of student empowerment is at the heart of competency-based education. Structures that distribute leadership enable educators to make good decisions for the benefit of their students. All students should benefit from competency education so as to ensure equity. Support and instruction should also be differentiated and timely. At traditional schools, some students have to fail before they receive support. Often, such "supports" are provided in the form of long-delayed opportunities for remedial learning. By using competency-based systems, schools create schedules and programs that provide additional support and guidance to struggling students. It is vital that students receive effective feedback based on the learning task in order to be able to learn, progress, and advance. An important part of research-informed pedagogy is meeting students where they are and building intrinsic motivation. Teachers in competency-based schools design instruction based on the understanding that "meeting students where they are" is the key to meeting students where they are. This is how they can cater instruction to a student's developmental, social, and emotional needs. Assessing students' learning and development helps teachers determine which supports will help them learn and progress. Unlike traditional education, which places an emphasis largely on summative assessment, most of which emphasizes the lower levels of Bloom's taxonomy: memorization, comprehension and application. When competency-based education is practiced, formative assessment is typically 
integrated into the cycle of learning to provide feedback that guides teachers' professional development and helps students master learning objectives. If students are not yet proficient, they should practice or revise until they are at the level of performance that demonstrates mastery of learning expectations. Assessment of student learning should be transparent, timely, draw on evidence from multiple sources, and communicate progress to students. In addition to using summative assessments as a tool to ensure that students are proficient, competency-based schools utilize them as an internal control tool to ensure that they are held to high standards consistently. In order for students to transfer knowledge and build higher order skills of analysis, synthesis, and evaluation, districts and schools develop the capacity for performance-based assessments.

By providing clear and highly credible information about students' progress toward graduation, students, teachers and families gain more trust in schools and advance equity. To ensure consistency in expectations of what it means to master knowledge and skills, mechanisms are in place. Across districts, schools, and even within classrooms, the traditional system includes a lot of variation: what is to be learned, what mastery to set, and how to grade student work. In this way, students are held to different expectations and are highly susceptible to bias: when teachers and leaders who are not aware of their biases are the final arbiters of student learning, they may unintentionally or intentionally perpetuate unequal outcomes for their students. Competency-based education, on the other hand, is concerned with how students can demonstrate they have learned. This is why a lot of schools participated in moderation processes so teachers could share expectations and understandings of standards. In a similar fashion, teachers calibrate their assessment methods so that they can assess learning consistently. It values openness and clarity with solid expectations of what is to be learned, the level of performance required for mastery and how students are doing. In addition to clear learning targets and expectations of mastery, students feel more empowered when they are able to choose how they learn and demonstrate proficiency.

The learning process and the success of students are supported by effective communication strategies. In order to ensure objectivity and transparency, grading policies separate academic performance from behavioral traits. In a classroom setting, students are expected and supported to practice and revise until they demonstrate proficiency in responding to feedback in an effective, timely and purposeful manner. While in traditional systems, students receive periodic report cards with A-F grades based on points earned from assignments, tests, and behavior. It is common for teachers to determine an individual's achievement based on their own grading system, which can lead to variability. The process of revising, which is a critical part of the learning process, is limited, and students are ranked based on their performance. However, in real and authentic learning processes, students take risks, fail, and revise. In other words, it is not merely following pacing guides that tell teachers to advance students in the curriculum even if they are not ready. In districts and schools with competency-based grading systems, educators use learning sciences. Failing and making mistakes are a part of learning. For the system of grading, the transparent common learning continuum provides the foundation. It is clear to students what they need to learn, how to demonstrate their learning, and how to demonstrate proficiency. In many schools today, students receive grades based on grade-level standards. In some schools, competency-based grading aligns with personalized learning paths. Additionally, learners advance based on attaining learning expectations (mastery) through personalized learning paths. Systematic implementation of competency-based education recognizes the fact that students may need more time to learn concepts and skills deeply. It may be necessary to scaffold their mastery if they have gaps in their knowledge and skills. If needed, students are provided with more support and time for instruction and progress is made when they are ready. It may be possible for students to pursue personalized pathways forward instead of linear progressions, based on the domains and learning targets.

\subsection{Attributes \& Benefits of CBE}

It is still imperative to identify the factors that contribute to students learning effectively and efficiently by identifying important attributes as well as the designed principles and strategies. For learning to be maximized, Neil O'Sullivan and Dr Alan Bruce (September, 2014) assert that teachers and learners need shared responsibilities and accountability, as well as supportive learning environments. In other words, effective learning needs to be lasting and capable of being applied in new and different situations with the guidance of all stakeholders.

94 Consortia Academia Publishing (A partner of Network of Professional Researchers and Educators) 
Furthermore, it requires the ability to mobilize, draw upon, and utilize psychosocial resources (including knowledge, skills, and attitudes) as needed in a particular situation. Communication, for example, is an important competency. For a better understanding, you might find this Venn Diagram useful before implementing CBE at your school.

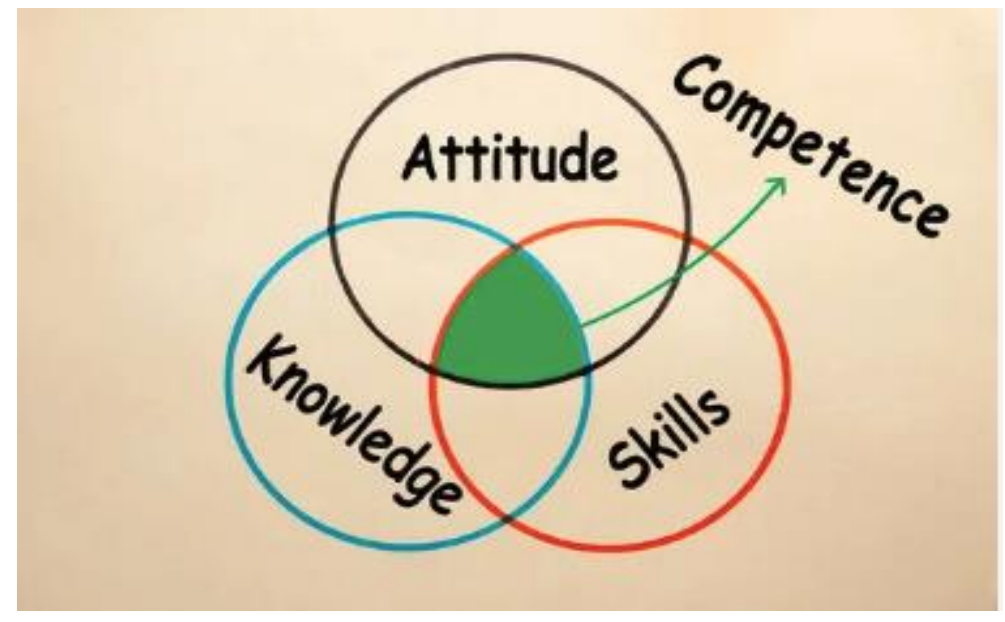

Figure 2: Dimensions of Competence. [Source: (Researchgate.net)]

As shown in the diagram, a competent person has a combination of skills, knowledge (cognitive component), attitudes (affective component), and behaviors (behavioural component) to flawlessly perform an activity. It is expected that the student is familiar with the information, should be able to apply acquired abilities, including aptitudes and natural abilities, and should also take into account the student's values, beliefs, attitudes, and culture before attempting to acquire competency. Implementing CBE means adhering to the holistic integration of these components. To create an effective learning environment, for instance, you need to make sure that the student demonstrates a certain behavior, a certain quality and a certain context. The learning style, abilities, and values of students need to be taken into account before implementing any learning outcomes. Besides students and teachers, families and communities are also directly impacted by understanding and applying these attributes. By incorporating inquiry, collaboration, academic discussion, peer feedback, cognitive coaching, and presentational strategies, teachers can provide students with an arc of learning that leads to independent mastery. Also, when families receive frequent, transparent feedback on how to understand, discuss, and support learning at home, they will be better informed about children's progress. Further, it can enhance clarity \& transparency that allows teachers and families to identify areas of strength and areas of need for additional support, especially in evaluating proficiency in different domains. Students' accomplishments and difficulties should be reported regularly by teachers. At our school (BXIHS), teachers provide narrative commentary to families about how a particular student engages with each domain as well as their notable accomplishments and struggles. When students have access to clear, timely, and actionable feedback all the time, they can focus on mastering the material independently. In this way, they will be able to be in charge of their learning. By doing so, they are better equipped to succeed as adults. They learn to become better learners, to take on responsibility for their education. Focusing on comprehensive feedback simplifies what's happening in the classroom for the learner and for the family.

Additionally, personalization of learning will be seamless. By studying each student's learning style and attitude, educators will be able to provide strategies and resources that best support individual needs. It also supports the shift and adoption of a very comprehensive assessment culture. A teacher should pursue resources and professional development that introduces different methods of assessing student progress and explains why these methods are effective. It's no secret that learning never stops - and by staying up to date with current trends, curriculum can be tailored to meet the needs of every student. In addition, students should take the time to understand themselves and their strengths. to perform well. By taking the student's needs and wants into account, we ensure that every student is challenged appropriately as he or she learns. Students with more self-knowledge about their learning methods and needs can be provided with individualized support to achieve college and career 
readiness. Regardless of their knowledge backgrounds or literacy levels, students feel empowered when they master a skill and can identify what's next. In this sense, competency-based education focuses on inclusiveness, equity, empowerment, flexibility and customization. For schools to be ready for implementation, they must recognize the importance of including students' experiences, abilities, and skills, professional practices, purposeful networks and partners, as well as school systems and cultures in their mission and vision statements.

\subsection{Breaking with Tradition: Innovation \& Equity - Sample Schools Implementing CBE}

There are already many schools that use competency-based education. They are transforming their learning and grading paradigms to create more equitable learning environments, while making learning more accessible to both academics and students of different cultures. Schools implementing the CBE model may describe themselves as youth-focused, culturally responsive, sustainable, mastery-based, performance-based, personalized learning, outcome-based, mastery-collaborative, or proficiency-based. Here are some of the schools that are implementing CBE across the United States of America.

$>\quad$ Latin School of Chicago

$>\quad$ Henrico County Public Schools, Virginia

$>\quad$ Hall-Dale Middle School, Maine

$>\quad$ List of Schools (as of 2017)

$>\quad$ New York City School

There are common traits between these schools in how they teach their students to advocate for themselves. In the CBE settings, 21 st century skills are clearly applied, and the "how of CBE" themes are developed: Learning takes place anywhere and anytime, authentic \& connected, student-owned, and community supported. In spite of their imperfections, most of these schools are finding competency-based education to be a huge benefit to students' lives, enabling them to practice their full potentials while they are in school, in the community, after school, and even preparing them for life beyond their school walls.

\section{Misconceptions, Challenges \& Suggestions}

It is the desire of every school to meet students where they are and allow them to exhibit what they have learned. Obviously, schools use different methods of achieving this goal. Leaders in schools often use many of the same terms and phrases to describe what they do to collaborate with students to achieve their full potential, but those words and phrases imply something entirely different. As a result of the varied strategies they used, some schools defined their competency-based education (CBE) differently, thus resulting in inconsistent student achievement.

As a consequence, some non-CBE practitioners may claim that students working at their own pace means they work for infinity. It is important to note that pacing does not mean that students can keep working at the same learning target for as long as they want. In other words, they are receiving instruction, as well as the opportunity to practice and reapply the materials until they have mastered them. As opposed to the traditional classroom, in which all learning must follow a district-issued pacing guide that dictates how long teachers should spend on a lesson before moving on. In that timeframe, there is little or no way to deal with those who do not grasp the concept. The class moves forward regardless of their level of understanding. Rather, it's a matter of covering material within the 180-day academic year. Rather, CBE's pacing entails intervening with the student to ensure mastery or to resolve misunderstandings. Having a well-organized (or well-managed) classroom will enable the teacher to work more closely with the student who is struggling. As an example, using the station rotation model, teachers can make time for small groups to work together to overcome learning blocks and develop scaffolds for addressing challenges. In other words, pacing can stifle creativity and inhibit student learning in order to accommodate the

96 Consortia Academia Publishing (A partner of Network of Professional Researchers and Educators) 
misconception that completing topics is equivalent to teaching and learning.

As well, students will be automatically responsible for their learning. If there is no relevant "why," students won't own their learning. When we implement CBE, we don't force students to advocate for themselves. Instead, we motivate them to explore and learn. The importance of connecting learning standards and objectives to the real world has increased with the advent of careers, technology advancement and other resources. I recall Eric Scheninger asking the audience at the 2017 Mid-Atlantic Conference on Personalized Learning in Baltimore a question that has stuck with me to this day: "Whose learning is it?" In other words, should students be motivated to learn what WE want or should students be motivated to learn what THEY want? As teachers, we're often frustrated that children do not care about topics that offer no relevance to them, and we're often unable to connect those state standards to the real world as well. In order to achieve ownership, teachers need to know who their students are, share relevant data, and provide actionable feedback that leads to mastery. In Bronx International High School, for example, students receive feedback that guides them in understanding who they are, what they have, and what they can accomplish, and that will motivate them to learn and think outside the box. The teacher models think-aloud for students in small groups to develop the metacognitive self-regulation skills needed to work independently. Teachers also encourage students to consider the questions they should ask themselves and how to make connections with previous learning. Moreover, we always encourage our students to take ownership of their learning through meaningful student-led weekly conferences.

Another misconception is that students can prove mastery with paper and pencil assignments. It's true that there are assessment types in a competency-based system that require paper \& pencil activities. In spite of this, there are several methods to demonstrate mastery, so we want to encourage them to own their learning. Hence, most teachers should be familiar with the theory of multiple intelligences, in which students are offered multiple ways to learn. The use of these ideas that promote individualization is more often neglected in lesson plans and assessments. At this point, teachers must also know the difference between assessing learning and assessing for learning. Using non-traditional methods of engaging students, developing creativity, and possibly revealing hidden talents means they are more likely to be able to apply 21 st century skills. The ultimate form of learning is the ability to teach others, so our job as teachers is to provide the necessary space and opportunities for that learning to occur. At this point of instruction and assessment, choice and agency are paramount. By giving students a sense of control, you can engage and motivate them even with small choices.

Along with the misconceptions, schools implementing competency-based education faced so many obstacles. Unorganized learning spaces, classroom management, inadequate preparations of teachers, uneven distribution of knowledge, technology utilization, providing real-time feedback. It's true, the road has many challenges, such as how teachers must adjust to their new roles, how students need to be more involved in their own education, or even how parents perceive the new grading system, which may significantly differ from what they are used to. Furthermore, when active learning is given to students with different learning styles together, such as explorations, practical projects, experiments, and research, difficulties may occur. Nevertheless, the benefits generally outweigh any challenges. To minimize these challenges, the school should provide teachers with a better overview and comprehensive students' data, notify teachers of the students' learning styles and modifications, create banks of personalized resources or activities including more meaningful assessment based on learning needs to maximize time. Also, it helps to provide possible names or business partners for career or internship matching, involvement of parents and guardians \& conferences, and a regular professional development plan to address feedback, fulfillment of purpose \& culture, teaching \& learning, and structure in the planning of the classroom.

\section{Reflections}

Since our school is a performance-based implementor and our populace are mostly immigrants that are nonEnglish speakers, Bronx International High School has been an advocate of competency-based education. Every school year, our school will discuss benchmarking, rubrics utilization and stakeholders' partnerships. We are making sure that teachers, parents and students understand the mission, vision and specific goals 
(academic/personal) of the school and each student. There will be workshops on how to use data especially the type of learners we cater for and what strategy, methods and approaches teachers should implement in and outside the four corners of the classroom. For example, since most of our students in 9th-10th grades (called as JI team) are non-English speakers, we usually assess (using IRLA, NYSITELL, MLS and SLAB testing) them to determine their abilities before talking to them about their learning goals. Also, our guidance counselor assigned to each team will have intake per student to know their personal background, quality of life (home conditions), culture and beliefs so that they can be assigned to the correct advisory groups. All possible structures that will be implemented are part of the workshops as well. While our 11th-12th grade (SI team) students with their assigned guidance counselor will have an intake about their performance in the previous years and what are the things they need to do for the current year and goal setting will follow. In addition, professional developments will be given to teachers every Monday and Tuesday to discuss Bloom's Taxonomy, 21st Century Skills and salient teaching methods/strategies (blended, flipped, cooperative-collaborative, experiential, project-based, problem-based \& others) and its implementation process. Our professional development team will give us the menu of training and workshops to choose from, if not our partner organizations such as the Consortium schools and International schools will provide us with other important training/workshops. In fact, on our website dated October 31, 2021 we have a PD about feedback and equitable grading practices. Aside from calling parents or students for feedback (academic or behavior), teachers will use Kinvolved and Jumprope for regular and purposeful feedback. Also, we allow our students to track their own weekly progress and this is across teams since students are trained to assess themselves through trackers per content class and should know what to relearn or retake for not mastering the skill with the expected proficiency level of 3(Proficient- can teach to others) or 4(Highly Proficient- can teach to others confidently).

Moreover, our school is a performance-based school with which we don't use numerical grades. We usually create adjusted rubrics given by the state for the JI team while the SI will follow the state PBAT rubric for each content class. Basically, each student has different goals and plans but whatever topics we do, they will definitely produce several outputs of their liking especially after small and big projects completion. Some of our students will be constructing models, researching and making websites, storybooks, will do explorations, interviews, develop portfolios for oral presentations, debates, project defense and immersion to the real environment of their chosen career pathways. I have observed that the majority of our teachers are using at least three methods of teaching in order to cater for all the needs of our students and to maintain the connections with them. For our junior institute (JI), cognitivism with experiential learning is very evident in most classes since we need to encourage our students to learn the basics (knowledge) by letting them experience the lessons/topics alone or together with partners or groups (assigned or of their choice). We are a big believer in connectivism as well due to the use of so many apps/softwares to assist learning especially in translations. However, our senior institute (SI) teachers are a big fan of constructivism with connectivism as tools to explore their lessons since students during this stage will be doing and applying what they learn from JI and from their internship experiences. For example in our math class exploring the essential question: How have immigration trends changed NYC? students have different stations and activities inside the classroom. With their goals in mind they will choose what activities they will perform during that day that conform with the learning outcomes. One station could be doing research about NYC immigration trends and its effect thru data gathering and analysis, second station is constructing a model house/building showing the living conditions of the NYC immigrants, 3rd station will be testing the water potability due to pollution since the influx of immigrants, 4th station is writing a narrative of the percentage of the types/races of NYC immigrants and 5th station is creating infographics or storybooks or posters showing the population increase/decrease or cause \& effect of NYC immigrants. Though it is tedious for teachers to prepare such a set-up, students' experience is important for we tried to model them how to become a critical/analytical thinker, communicator, collaborator, creative thinker, with quality character and most especially a good/better global citizen.

Furthermore, our main goal as a school is to help our students understand what, how and why they're in school and to decide where they are going after graduation though some of them are already working to fulfill their

98 Consortia Academia Publishing (A partner of Network of Professional Researchers and Educators) 
chosen career while waiting for college acceptance. Our school is committed to guiding them to be a valuable asset to the community by allowing and introducing them to our partners and other stakeholders like SYEP program, Rocking the Boat Organization, BEAM Center, Woodlawn Cemetery, Crew Connect Trip NYC, Chase Bank, Outward Bound and other significant organizations to not only improve their lives but to transform other lives.

Consequently, there are challenges we encountered in implementing a competency-based model in our school such as needed more time for lesson and activity preparations, dependency on tech for translations where some students can't converse freely their thoughts to others even after 9th grade especially our SIFE students (interrupted formal education), inadequate resources (school budget) due to budget prioritizing, less to no parental support (personal \& academic) since parents are working to meet daily household needs, language barriers and non-formal education. Another is the implementation of the "No Child Left Behind Act of 2001" where most schools including ours didn't come close to achieving the 100-percent-proficiency mandate, which experts never considered a realistic target. If our students are aged 18 and haven't met the proficiency level, they will still graduate by going to another specialized institution. But the advantages a competency-based model gives to our school are far more than the negative aspects mentioned above. We are confident that we have helped students to see and own learning, learn at their own pace, motivate to learn \& relearn and can be better individuals in the community. We are always reminded to use the growth mindset approach to guide our students. This means that students hear "not yet" or "approaching mastery," instead of "you fail." Everyone understands how to succeed, because criteria for mastery and proficiency are shared and "unpacked" from the start. Basing grades on learning outcomes and using rubrics narrows the chance of implicit bias in grading. The use of culture-sensitive curriculum and classroom strategies leads to students being able to work well with others who are very different from themselves. Students gain perspective and power as they develop critical consciousness, enabling them to express what needs to change and to "be the change" they wish to see.

\section{Conclusion/Future Directions}

For teachers, competency-based education brings depth and value to the curriculum. Students become more involved in long-term progress as the focus of assessment shifts away from numbers and percentages. These students are more apt to become engaged in learning and take greater risks. Using student rankings to predict future contributions and prospects is a practice best left to the past and has been discovered not to be helpful for most of today's active learners. By using competency-based assessments, students receive more detailed information that promotes authentic learning and connection. It helps develop a culture of equity and inclusivity and prepares students for life beyond the walls of their school. Children who participate in competency-based education are able to demonstrate mastery of a topic no matter when they are studying it or where they are studying it. Although this system presents school leaders with unique challenges, they will greatly benefit from overcoming those challenges.

Additionally, students, parents, and teachers alike must understand how a person learns best (style). All parties involved in the education process should also know exactly what the expected outcomes of the learning process are, as well as students taking responsibility for their learning. Similarly, teachers will motivate their students to learn (goal-oriented) and become ethical individuals and practitioners. They should be critical thinkers, able to assess their own learning and performance, and committed to continuous learning. These beliefs and practices help teachers plan what type of methods or strategies to incorporate into their teaching pedagogy so that learning \& teaching are efficient $\&$ effective. The teacher may, for example, provide a few choices about how students are going to learn or assess. Throughout the school year, as students develop a better understanding of who they are as learners, they will be able to present their learning based on their own choices. Students are empowered to make these choices. The unique aspect of this program is that we are constantly innovating in order to meet students' needs.

Further, design principles can help us challenge the many traditional habits and customs that influence our schools and can push us to think beyond the current paradigms for organizing schools in a way that promotes equity and provides a framework of shared language for all CBE practitioners. In spite of the greater challenges, 
all schools in the CBE network must be willing to question, critique, disagree, and engage in joint inquiry. This will enable CBE implementers to push for high-quality design, innovation, and continuous improvement. With design principles, educators can reflect on and develop more effective and aligned practices, approaches and methods using the different lenses. We hope, however, that additional tools and resources can be developed, knowing the challenges we encountered. To ensure that competency-based cultures, structures, and pedagogies are producing higher achievement and greater equity, there must be more stakeholders involved in co-design initiatives.

It is also imperative that teachers, parents, and partners work together without reservation in order to accelerate the process of transferring and developing knowledge. Our work also must be driven by an urgency to better serve and educate students with high-quality approaches that can provide high-quality educational environments to more students without excuses. The achievement of each school's mission-vision depends on how we can deliver authentic learning, accessible to all, anytime and anywhere, that is student-owned and supported by the whole community. We educate today's children to be tomorrow's innovators. It is perhaps controversial to say this, but educating students holistically is equivalent to developing the world and transforming lives. In this way, we always keep reminding ourselves: "If we tell learners to complete a task, we get compliance with minimal understanding. However, when we EMPOWER learners to investigate how to make an impact on the world, we INSPIRE problem SOLVERS and INNOVATORS. Thus, let them experience, grapple, learn and share".

\section{References}

A method for the evaluation of the quality of games ... (n.d.). Retrieved February 21, 2022, from https://www.researchgate.net/publication/329811263_A_METHOD_FOR_THE_EVALUATION_OF_T HE QUALITY OF GAMES FOR COMPUTING EDUCATION

BIHS. (n.d.). Retrieved February 21, 2022, from https://sites.google.com/bronxinternationalhs.com/bxihs

Gross, B., Tuchman, S., \& Patrick, S. (2018). A national landscape scan of personalized learning in K-12 education in the United States. Vienna, VA: iNACOL. Retrieved from http://www.aurorainstitute.org/wp-content/uploads/iNACOL_ANationalLandscapeScanOfPersonalizedLearning.pdf

Juraschka, R. (2019, March 27). Competency Based Education: What is it, and How Your School Can Use it. Retrieved from https://www.prodigygame.com/in-en/blog/competency-based-education/\#models

Kellogg, S. (2018). Competency based education: Best practices and implementation strategies for institutions of higher education. Doctorate in Education. 3. https://digitalcommons.csp.edu/edd/3

Levine, E., \& Patrick, S. (2019). What is competency-based education? An updated definition. Vienna, VA: Aurora Institute. Retrieved from https://aurora-institute.org/wp-content/uploads/what-is-competencybased-education-an-updated-definition-web.pdf

Motivis Learning. (2017). What is competency-based education? Retrieved from https://motivislearning.com/competency-based-education/

O’Sullivan, N., \& Bruce, A. (2014, September 22). Teaching and learning in competency based education. Retrieved from https://www.researchgate.net/publication/269810124_Teaching_and_Learning_in_Competency_Based Education

Our schools. Competency Collaborative. (n.d.). Retrieved February 21, 2022, from http://www.competencycollaborative.org/our-schools-2\#overview

Powell, A., Kennedy, K., \& Patrick, S. (2013, October). Mean What You Say: Defining and Integrating Personalized, Blended and Competency Education. p. 7, Retrieved April 29, 2016, from_ http://www.inacol.org/resource/mean-what-you-say-defining-and-integrating-personalized-blended-andcompetency-education/

Sturgis, C. (2016, March 29). Detailed Definition of Competency Education. Retrieved April 29, 2016, from_ http://competencyworks.pbworks.com/w/page/67945372/Detailed Definition of Competency Education

Sturgis, C., Patrick, S., \& Pittenger, P. (2011). It's not a matter of time: Highlights from the 2011 CompetencyBased Learning Summit. Retrieved from http://www.aurora-institute.org/wp- 
content/uploads/iNACOL_Its_Not_A_Matter_of_Time_full_report.pdf

Team@masterycollaborative. Mastery Collaborative: Division of Teaching and Learning NYC DOE: Shifting

The Paradigm of Learning \& Grading in NYC Schools http://www.masterycollaborative.org

Traditional education versus competency-based education. Knowledge Works. (2019, July 17). Retrieved

February 21, 2022, from https://knowledgeworks.org/resources/traditional-versus-competency-

education-infographic/

Traditional education vs competency based learning. (n.d.). Retrieved February 21, 2022, from

https://leg.mt.gov/content/Committees/Interim/2019-2020/Education/Meetings/Nov-2019/cbeversus-traditional-education.pdf

Understanding competency-based education. (n.d.). Retrieved February 21, 2022, from https://www.ecs.org/wpcontent/uploads/CBE-Toolkit-2017.pdf

XQ, T. (2020). What is Student-Centered Learning and Why is it Important? Retrieved August 25, 2020 from_ https://xqsuperschool.org/rethinktogether/what-is-student-centered-learning/ 
Cuyacot, E. P., \& Cuyacot, M. T.

102 Consortia Academia Publishing (A partner of Network of Professional Researchers and Educators) 